Research Article

\title{
Reinforcement Effect of Inclined Prestressed Concrete Pipe Piles on an Inclined Soft Foundation
}

\author{
De-quan Zhou $\mathbb{D}^{D}$, Chen-xi Feng $\left(\mathbb{D}\right.$, Liu-xi Li $\mathbb{D}^{D}$, Yi Zhou ${ }^{(D)}$, and Qin Zhu ${ }^{\circ}$ \\ School of Civil Engineering, Changsha University of Science \& Technology, Changsha 410114, China \\ Correspondence should be addressed to Chen-xi Feng; fengchenxi199011@163.com
}

Received 25 February 2020; Revised 14 July 2020; Accepted 23 July 2020; Published 20 August 2020

Academic Editor: Francesco Colangelo

Copyright ( 92020 De-quan Zhou et al. This is an open access article distributed under the Creative Commons Attribution License, which permits unrestricted use, distribution, and reproduction in any medium, provided the original work is properly cited.

\begin{abstract}
The embankment slope is vulnerable to slip and collapse, when prestressed concrete pipe (PCP) piles are used to reinforce the inclined soft foundation to bear the load of the embankment. Accordingly, this study puts forward new programs for strengthening embankment foundation with inclined, rather than vertical, PCP piles. Based on an actual engineering accident with embankment slope collapse, this study establishes a finite element model, accompanied by analysis of engineering characteristics and reinforcement effects of the foundation. The main conclusions are drawn as follows: (1) when a pile-supported foundation is used to strengthen the inclined soft foundation, PCP piles in the lower part of the embankment are subjected to bending moments, with their maximum value appearing in the upper part of the PCP pile at the embankment slope foot. During the embankment filling, the maximum pile bending moment may reach the ultimate bending load, resulting in bending failure accompanied with large lateral displacement and even slope collapse. The maximum horizontal displacement of the foundation is located at the foot of the embankment slope. (2) Reinforcement using inclined PCP piles contributes to smaller maximum pile body bending moments than that using vertical PCP piles and loading berms, and such contribution is enhanced when the inclination angle of PCP piles in the lower part of the slope gets larger. Therefore, inclined PCP piles with high angles are optimum in improving the overall stability of the foundation. (3) Compared with vertical PCP piles, inclined PCP piles contribute to smaller horizontal displacement and vertical settlement in foundation reinforcement, which means better reinforcement effects. Moreover, as the inclination angle of PCP piles increases, the maximum displacement decreases rapidly, associated with greatly enhanced lateral stability.
\end{abstract}

\section{Introduction}

When filling high embankments on an inclined soft foundation, reinforcement is significantly necessary due to insufficient foundation-bearing capacity. Currently, pilesupported foundations are widely used due to their effectiveness in horizontal soft foundation reinforcement. They are subjected to many modes of failures, as demonstrated in extensive centrifugal tests [1-6]. Specifically, cement mixing piles are vulnerable to large lateral displacement, as well as shear and bending failures, which ultimately render foundations subjected to large-area lateral sliding instability. In comparison, rigid piles, typically represented by prestressed concrete pipe (PCP) piles, have greater flexural strengths and pile stiffness and, thus, contribute to better soft foundation reinforcement. Zheng et al. [7-9] numerically and experimentally demonstrate the vulnerability of rigid pilestrengthened soft foundations to lateral slip and instability failure under the load of the upper embankment. Rigid piles at different locations present different stability controls on the embankment. Specifically, those in the middle-lower part of the embankment mainly bear the vertical load of the upper embankment, which means they are primarily in the compression zone (Figure 1). In comparison, those in the lower part of the embankment slope are also subjected to the horizontal earth pressure in addition to the vertical load, and thus, they are in the bending-shear zone (Figure 1). When the rigid pile-strengthened foundation is subjected to the load of the upper embankment, piles in the bending-shear zone firstly get bended and overturned, followed by 


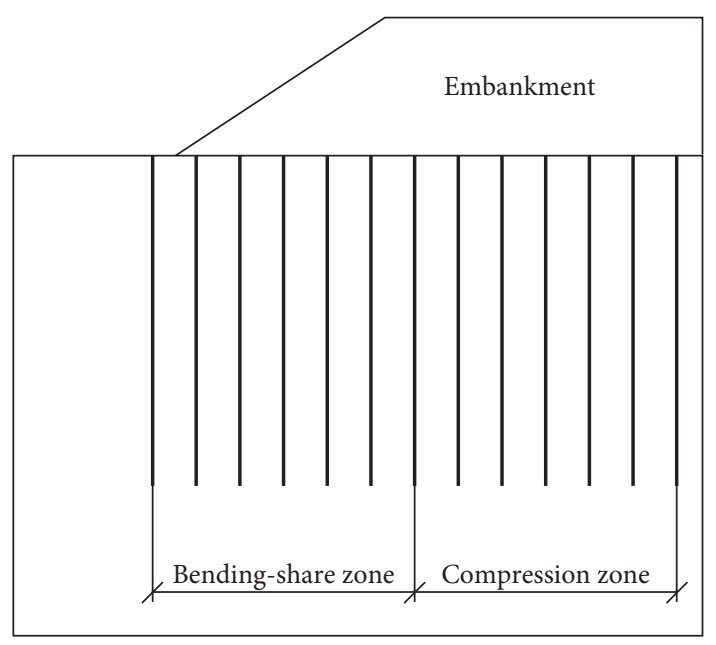

Figure 1: Different zones of piles.

expansion of such failures to the other piles, resulting in the overall instability damage of the embankment.

Some scholars have also carried out related research on the engineering characteristics of the pile-supported embankment on an inclined soft soil foundation. Liu and Zhang [10] found that the settlement and displacement of the foundation were not symmetrical, the whole foundation moved to the outside of the slope, and the largest displacement value occurs at the slope foot of the embankment. Bi et al. [11] studied the deformation characteristics and failure mode of the pile composite foundation on the inclined soft foundation by the geotechnical centrifugal model test. They considered that the potential failure mode of the foundation is mainly the overturning and horizontal movement of the pile body by lateral stress. $\mathrm{Gu}$ et al. [12] researched failure modes of an inclined natural soft foundation, CFG pile composite foundation on a horizontal soft foundation, and CFG pile composite foundation on an inclined soft foundation. It is considered that, under the action of embankment load, the CFG piles are prone to breakage and, finally, form a rigid short pile moved with soft soil. The fracture of the CFG pile on the inclined soft foundation is more concentrated in the downhill direction, and the influence range is relatively large.

A similar phenomenon is also observed by Xie et al. [13] during their tests on rigid pile-reinforced inclined strata. Given the aforementioned, when the pile-supported embankment is constructed on the inclined soft foundation, the foundation is prone to collapse due to overall insufficient stability. PCP piles in the bending-shear zone are critical in stabilizing the embankment, and countermeasures should be accordingly taken in the practical application of them. Nowadays, the loading berm (Figure 2(a)) has been commonly used at the outside part of the embankment slope in practical engineering to increase the overall stability. Specifically, such a loading berm can enhance the sliding thrust of the foundation to a certain extent when it is used on the inclined soft foundation. However, it may also aggravate the instability failure of the slope. Therefore, given its potential cons and pros, further research is needed to clarify the reinforcement effect of the loading berm.

Compared with vertical piles, inclined piles have less lateral displacement due to their stronger lateral bearing capacity when subjected to lateral loads [14]. Therefore, they can be set in the bending-shear zone to prevent the pile body from overturning (Figure 2(b)). Meanwhile, vertical PCP piles can be arranged in the compression zone to bear the vertical load (Figure 2(b)). However, there has not been any reported actual project or theoretical research using this kind of reinforcement program. As the good reinforcement characteristics, the composite structure has been used more and more in practical engineering [15-19]. Inclined piles have been proven to have much smaller vertical bearing capacity and yet larger horizontal bearing capacity than the vertical ones [20-23]. Since inclined PCP piles in the bending-shear zone are subjected to both vertical loads from the upper embankment and horizontal loads, it is challenging to well understand their mechanical characteristics and reinforcement effects.

Based on an actual engineering failure with embankment slope collapse, this study analyses the failure mode of the pile-supported embankment on the inclined foundation by field survey before the slope collapse. With reference to the field measured data, a finite element analysis model is established to compare reinforcement effects of programs using vertical PCP piles, the inclined PCP piles, and loading berms, accompanied by the investigation into the pile body deformation characteristics. Results of this study are expected to provide a reference for engineering application of this new soft foundation reinforcement program.

\section{Engineering Accident Analysis}

2.1. Engineering Accident Background. The engineering accident takes place on the Xiaoxianhong Expressway of Wuhan Ring Road, which is located in Hubei Province, China. One of the embankments is located in the inclined soft foundation section. According to the design requirements, the maximum filling height of the embankment is $9 \mathrm{~m}$, and PCP piles are used to strengthen the soft foundation. Specifically, these PCP piles have a diameter of $0.4 \mathrm{~m}$, a pile spacing of $1.5 \mathrm{~m}$, and an average reinforcement depth of $20 \mathrm{~m}$. Outline of the actual engineering and soil layer distribution are shown in Figure 3.

The embankment filling process is accompanied by the gradual occurrence of cracks on the top of the embankment and tendency of the slope to slip. When the embankment filling height reaches $7.64 \mathrm{~m}$, large-area slip and collapse (Figure 4(a)) occur suddenly on one side of the slope. After excavating and cleaning the embankment, it is found that PCP piles in the lower part of the sliding slope are broken, with large lateral displacement observed at the pile top (Figure 4(b)).

According to the damage characteristics of the embankment slope, as well as the on-site geological survey and the PCP pile arrangement, the embankment damage is schematically illustrated, as shown in Figure 3. The collapse area is located on the shoulder and slope, where there is an 


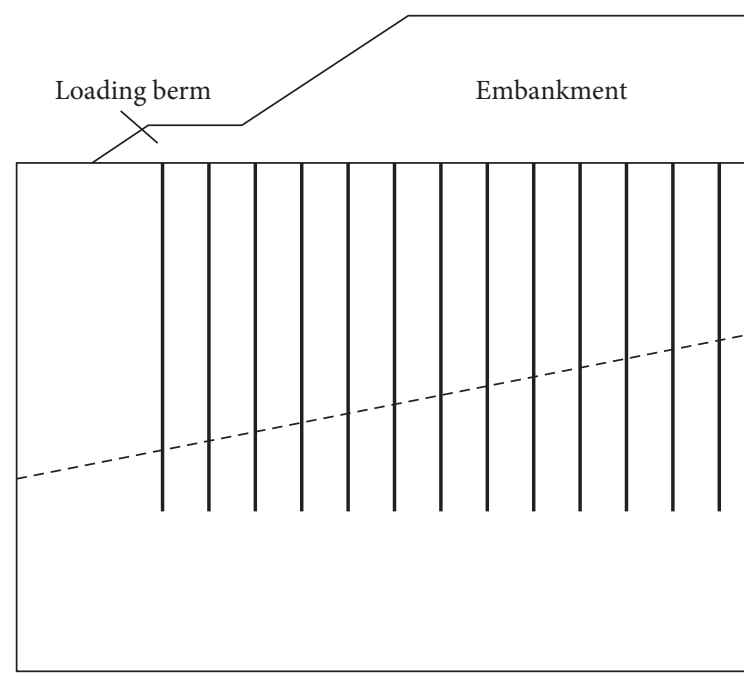

(a)

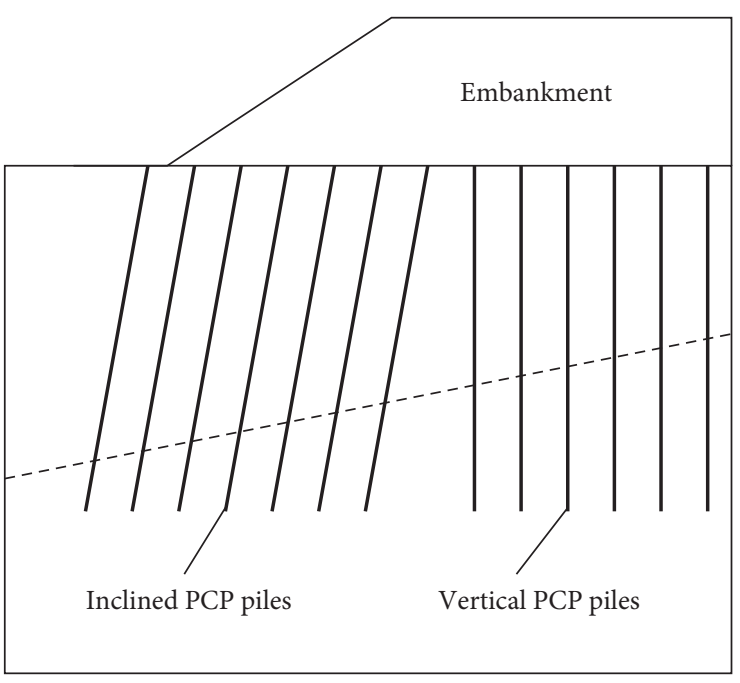

(b)

FIGURE 2: Models of pile-supported embankments. (a) Reinforcement model of the loading berm and (b) reinforcement model of inclined PCP piles.

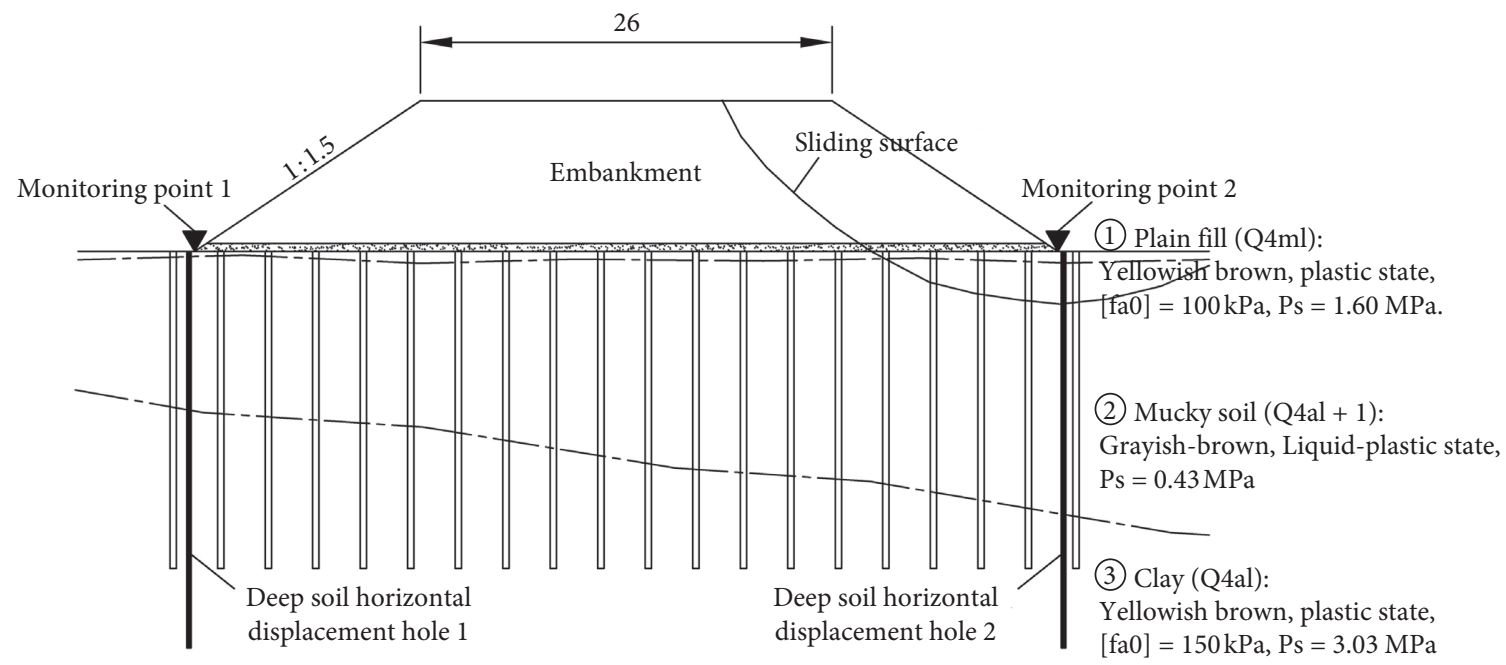

Figure 3: Diagram of the subgrade section.

obvious sliding surface that involves piles at the lower part of the embankment slope. When subjected to lateral load, the pile body gets broken, followed by large lateral displacement and consequent lost reinforcement effects. In this context, insufficient lateral bearing capacities of PCP piles in the lower part of the embankment slope are primarily responsible for the slope collapse.

\subsection{Field Test Analysis. Two displacement monitoring} points and two deep soil horizontal displacement monitoring holes are placed at the foot of the embankment slope (Figure 3). Variation of the position of the foundation under the embankment is measured during filling. Figure 5 shows the horizontal displacement and vertical settlement changes of the monitoring points during the embankment filling, both of which present increasing trends as the embankment filling height increases. Specifically, both the horizontal displacement and vertical settlement of monitoring point 2 are obviously larger than those of monitoring point 1 . Moreover, the horizontal displacement of monitoring point 1 gradually slows down as the embankment height grows, while that of point 2 continuously increases, suggesting an unstable state (Figure 5(a)). As the filling height reaches $6 \mathrm{~m}$, certain uplifting occurs at the foot of the slope at monitoring point 2 (Figure $5(\mathrm{~b})$ ).

As the embankment filling height increases from $4 \mathrm{~m}$ to $7 \mathrm{~m}$, the displacement of the soil body at two monitoring points is found to be negatively correlated to the soil body depth with reference to the ground surface (Figure 6). Specifically, large displacement mainly occurs in the soil body that is $0-10 \mathrm{~m}$ deep from the ground surface. Moreover, compared with the monitoring hole 1 , the soil body in hole 2 has larger displacement at the same depth and a larger 


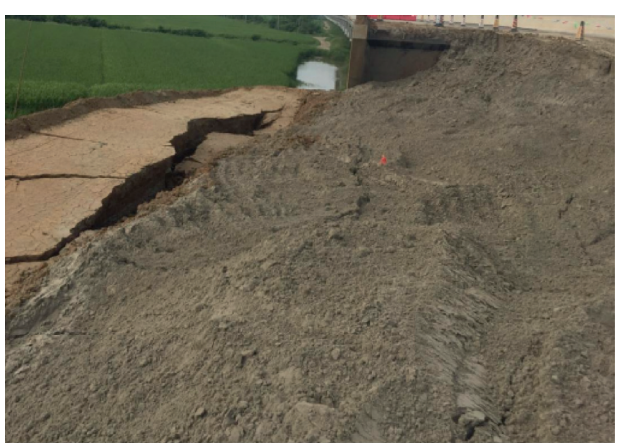

(a)

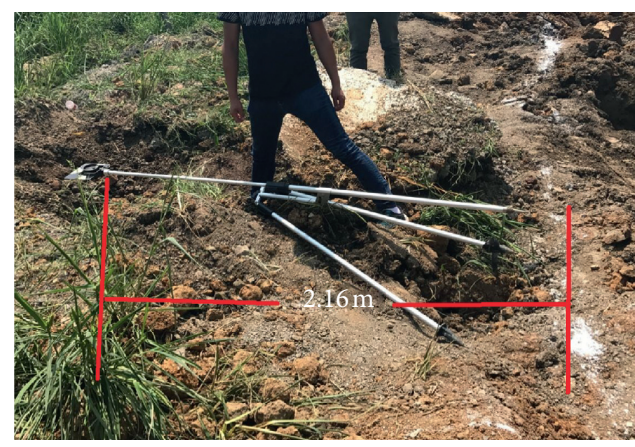

(b)

Figure 4: Subgrade collapse site. (a) Collapse area and (b) axis offset of the pile top.

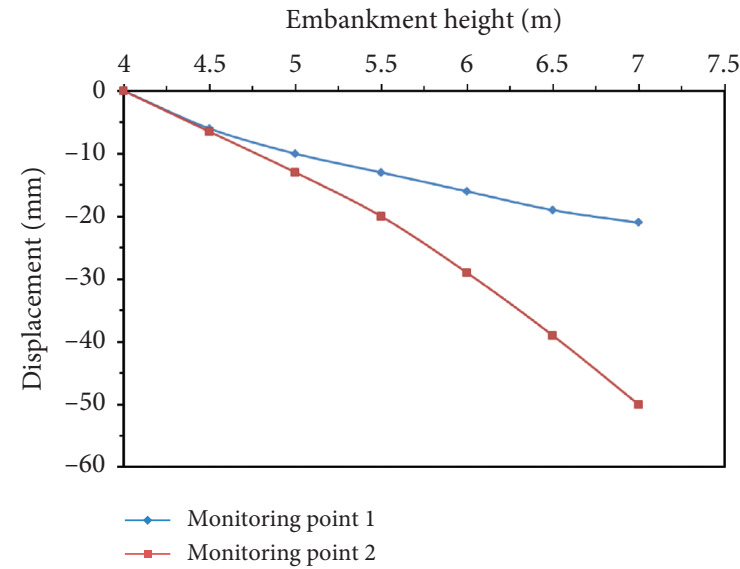

(a)

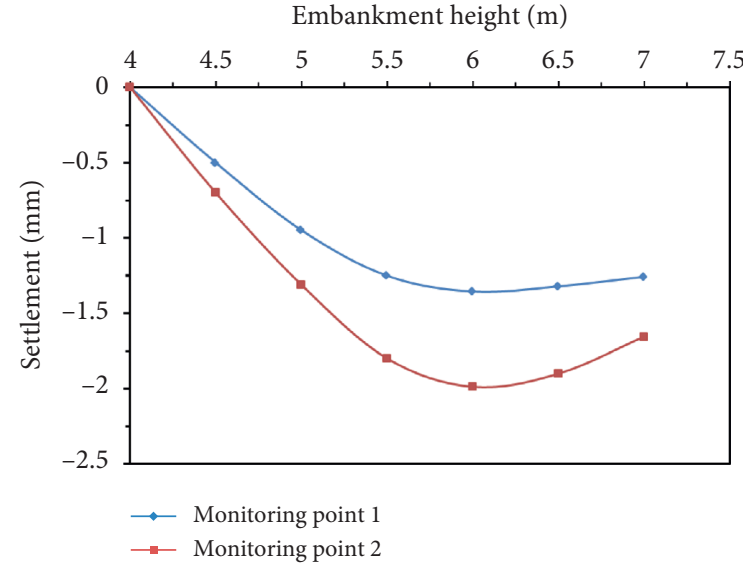

(b)

Figure 5: Displacement of the soil body at monitoring points. (a) Horizontal displacement and (b) settlement.

depth that displacement converges to a constant value (Figure 6).

According to the abovementioned analysis of the field data, the lower soil is subjected to lateral displacement during embankment filling, due to the obviously insufficient slope stability in the downhill direction of the inclined formation. In this case, the slope is vulnerable to collapse, and thus, efforts should be made to reinforce the horizontal stability of the slope.

\section{FEM Analysis}

3.1. Establishment of the FEM Model. After occurrence of the engineering accident, a program with inclined PCP piles is proposed for reinforcing the embankment slope foundation (Figure 2(b)). However, it is challenging to determine the design parameters and elaborate the reinforcement effect. Accordingly, this study establishes a finite element model, with considerations of distributions of soil layers, PCP piles, and embankments in actual projects. The optimum reinforcement program is identified through evaluation of reinforcement effects and stress characteristics of inclined PCP piles with different angles, results of which can provide a reference for the treatment of the engineering accident. In

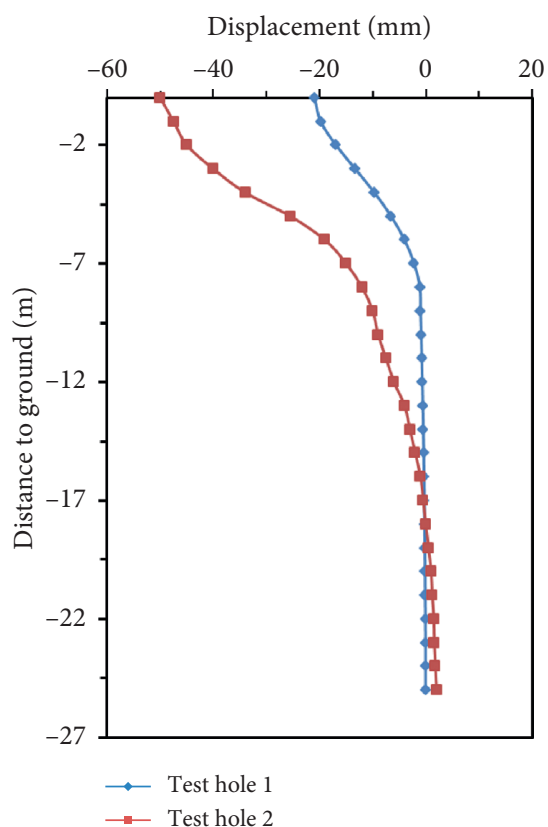

FIGURE 6: Displacement of soil body corresponding to an embankment filling height increase from $4 \mathrm{~m}$ to $7 \mathrm{~m}$. 
addition, a model of reinforcement with the loading berm (Figure 2(a)) is established for comparison.

In the finite element analysis model, deformation characteristics of the half embankment are simulated and analyzed. The top surface of the half embankment is $13 \mathrm{~m}$ wide and $9 \mathrm{~m}$ high. The embankment slope is $1: 1.5$. Two kinds of soil layers are set in the lower part of the embankment, which share high similarity with the actual case. The slope of the contact surface is set to $1: 7$. In order to alleviate boundary effects, the lower layer of the embankment in the model is set to be as large as possible, which is $80 \mathrm{~m}$ in the $X$-direction and $50 \mathrm{~m}$ in the $Z$-direction. The groundwater level in the model is set to be $-1 \mathrm{~m}$ according to the actual condition. Designed and actual layouts of the finite element analysis model are shown in Figure 7.

According to section specifications and layouts of PCP piles in the actual project, five rows of vertical piles are set in the middle-lower sections of the embankment, and six rows of inclined piles are set in the lower part of the embankment slope. Influences of pile inclination angles are investigated through designing four programs, denoted as Programs A, $\mathrm{B}, \mathrm{C}$, and $\mathrm{D}$, respectively (Table 1 ). Moreover, a reinforcement program with a loading berm, denoted as Program E, is also set up for comparative analysis.

Grid convergence tests are carried out to evaluate the calculation accuracy and duration, which demonstrate $1 \mathrm{~m}$ to be a proper soil grid size. The finite element model is divided by 8 -node 3D grids, which generate a total of 301623 nodes and 76202 units. Displacements at the model bottom in $X$-, $Y$-, and $Z$-direction and axial displacements at the model side surfaces are constrained. In order to mimic the actual embankment filling process, a total of 9 steps are implemented in the model, with an incremental embankment filling height of $1 \mathrm{~m}$.

3.2. Model Material Parameter. In the finite element model, the PCP pile is simulated by the linear elastic model, which generally divides soil layers into three types, namely, the embankment fill, the upper mucky soil, and the lower silty clay, and they are all simulated by the Mohr-Coulomb model. According to the actual geological investigation data in the background project, model material parameters are preliminarily determined to establish a model with a single pile under the static load. A vertical load of $1000 \mathrm{kN}$ is applied to the top of the PCP pile in ten stages to obtain the Q-s curve, which is constantly compared with the Q-s curve with identical conditions in the actual case. Ultimately, through gradual adjustment, good matching is achieved between Q-s curves using simulated data and measured data (Figure 8).

The bearing capacity of the single pile in the model is consistent with that in the actual engineering condition. Also, the displacement data of Program A in the finite element analysis model are in good agreement with the those of the original project. Table 2 shows parameters of materials that are finally used in the model, which are believed to meet the needs of simulation analysis.

\section{Results and Analysis}

4.1. Horizontal Deformation of the Foundation. The foundation deformation in the horizontal direction reflects the overall stability of the foundation in different reinforcement programs. Figure 9 shows horizontal deformation nephograms of the foundation in different reinforcement programs when the embankment filling height reaches $9 \mathrm{~m}(162 \mathrm{kPa})$ (without consideration of the influence of the PCP pile failure). The following conclusions can be drawn:

(1) Program A (Table 1) is featured by large horizontal displacement in the upper embankment and the top surface of the soft soil layer. In the upper embankment, horizontal displacement is mainly concentrated in the slope, and it decreases in the direction away from the embankment foot, reaching the maximum at the slope foot. In comparison, at the top surface of the soft soil layer, there is a clear arcshaped sliding area. The abovementioned deformation characteristics are consistent with those reported by $\mathrm{Gu}$ et al. [12], which proves reliability of the finite element model.

(2) Programs B, C, and D share similarity with Program A, in terms of the foundation deformation characteristics. In comparison, as the pile inclination angle increases, the horizontal displacement deformation area decreases, with Program D having the smallest area.

(3) There also exist large areas with horizontal displacement in the upper embankment and the top surface of the soil layer in Program E. Compared with Program A, the displacement area in Program E is smaller, which proves the capacity of the loading berm to effectively enhance the overall stability of the embankment. However, the displacement areas in Programs B, C, and D are also smaller than those in Program A, which is attributed to the better lateral stability reinforcement by inclined piles than that by loading berms.

Figure 10(a) shows variations of maximum displacement values at the embankment slope foot during loading on piles with different inclination angles, while Figure 10(b) shows variations of maximum displacement values with pile inclination angles under different embankment loads. The maximum lateral displacement of the embankment foot increases with loads in all programs. Specifically, Program A has the largest displacement growth rate, followed by Programs E, B, C, and D. Therefore, it can be inferred that inclined piles have better lateral reinforcement effects than loading berms. Moreover, when the inclined pile is used for reinforcement, the lateral stability is enhanced as the pile inclination angle increases.

According to the abovementioned analysis, the lateral movement area and the lateral displacement value of the foundation are obviously reduced as the pile inclination angle increases, accompanied by significantly enhanced lateral stability of the foundation. In other words, a properly 


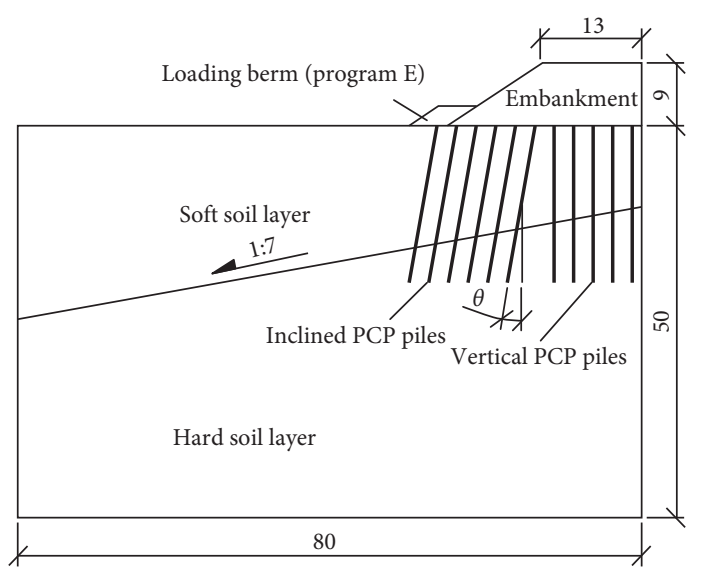

(a)

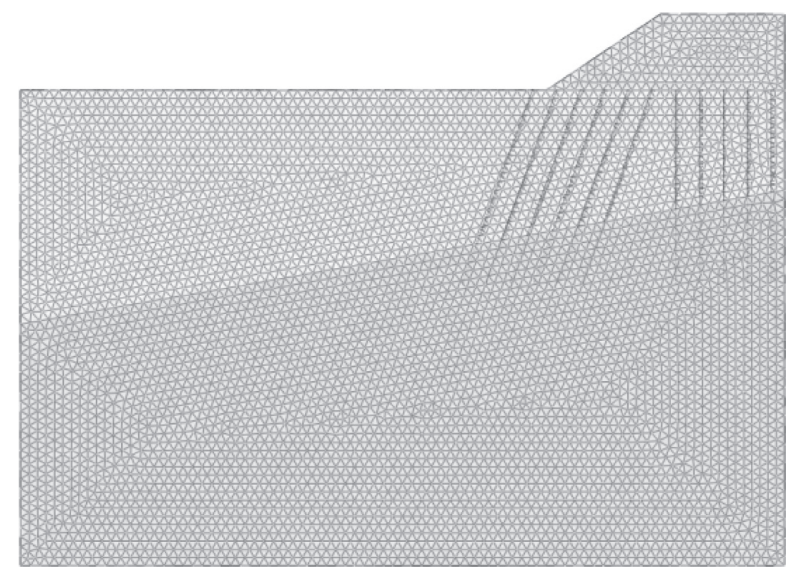

(b)

Figure 7: Fem model. (a) Model layout and (b) the actual model.

TABLe 1: Model configuration.

\begin{tabular}{lccccc}
\hline $\begin{array}{l}\text { Program } \\
\text { number }\end{array}$ & $\begin{array}{c}\text { Inclination angle of PCP } \\
\text { piles }\left(^{\circ}\right)\end{array}$ & $\begin{array}{c}\text { Size of the loading berm } \\
(m \times \mathrm{m})\end{array}$ & $\begin{array}{c}\text { Section size of PCP piles } \\
(\mathrm{mm})\end{array}$ & $\begin{array}{c}\text { Pile spacing } \\
(\mathrm{m})\end{array}$ & $\begin{array}{c}\text { Pile length } \\
(\mathrm{m})\end{array}$ \\
\hline A & 0 & - & & & \\
B & 10 & - & $400 \times 70$ & 2.5 & 20 \\
C & 20 & - & & & \\
D & 30 & - & & & \\
E & 0 & $5 \times 2.5$ & & & \\
\hline
\end{tabular}

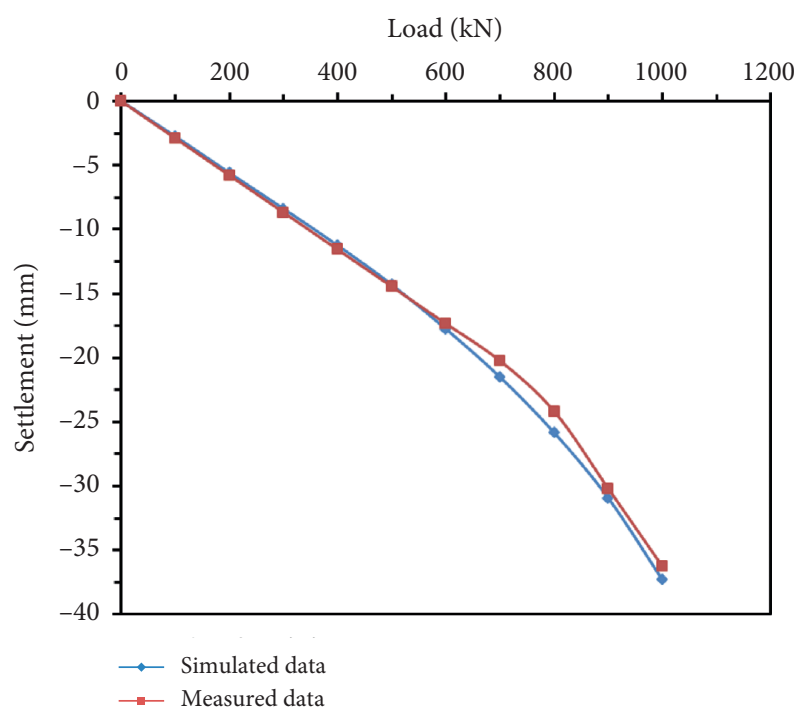

Figure 8: Load-Settlement curves.

large PCP pile inclination angle has a good lateral reinforcement effect.

4.2. Vertical Settlement of the Embankment. Since an inclined PCP pile has significantly lower vertical bearing capacity than a vertical PCP pile [18], its vertical settlement under the load of the embankment slope is a key factor to be concerned. Figure 11 shows settlement distribution curves of the embankment bottom surface in different reinforcement programs when the embankment filling height reaches $9 \mathrm{~m}(180 \mathrm{kPa})$. The $X$-axis in the figure indicates the distance to the embankment slope foot, with the position at $X=0$ referring to the embankment slope foot and the position at $X=12 \mathrm{~m}$ referring to the top of the embankment slope. The $Y$-axis represents the vertical settlement of the bottom surface of the embankment.

(1) Different programs share similar settlement distribution regularity, with the smallest vertical settlement at the foot of the embankment slope $(X=0 \mathrm{~m})$ and increasing vertical settlement in the direction away from the slope foot, reaching the maximum value at the center of the embankment $(X=23 \mathrm{~m})$.

(2) Different programs vary from one to another in terms of the absolute vertical settlement values. In the lower part of the embankment slope $(X<12 \mathrm{~m})$, Program D has the largest vertical settlement, followed by Programs C, B, and A. That is, as the pile inclination angle increases, the vertical settlement of the embankment slope bottom surface increases, though the magnitude of the increase is not significant. In the middle part of the embankment bottom $(X>12 \mathrm{~m})$, Program A has the largest vertical settlement, followed by Programs B, C, and D. Therefore, it is indicated that the vertical settlement value in the middle part of the embankment bottom decreases as the pile inclination angle increases.

Though inclined piles have smaller vertical bearing capacities than the vertical ones, the vertical settlement of the PCP pile-reinforced foundation is hardly influenced, due to 
TABLe 2: Model material parameters.

\begin{tabular}{lcccccccc}
\hline Soil layer & Model & $\mathrm{E}(\mathrm{kPa})$ & $v$ & $\gamma\left(\mathrm{kN} \cdot \mathrm{m}^{-3}\right)$ & $\varphi\left(^{\circ}\right)$ & $\mathrm{c}(\mathrm{kPa})$ & $e_{0}$ & $k\left(\mathrm{~m} \cdot \mathrm{s}^{-1}\right)$ \\
\hline Mucky soil & Mohr-Coulomb model & 7850 & 0.38 & 17 & 4.4 & 5.62 & 1.1 & $2 e-8$ \\
Silty clay & & 57000 & 0.25 & 18 & 18.15 & 36.21 & 0.5 & $2 e-7$ \\
Embankment soil & & 18400 & 0.33 & 18 & 16.7 & 37.6 & 0.73 & $2.08 e-7$ \\
PCP pile & Linear elastic model & $2.7 \times 10^{7}$ & 0.17 & 25 & $\sim$ & $\sim$ & $\sim$ & $\sim$ \\
\hline
\end{tabular}

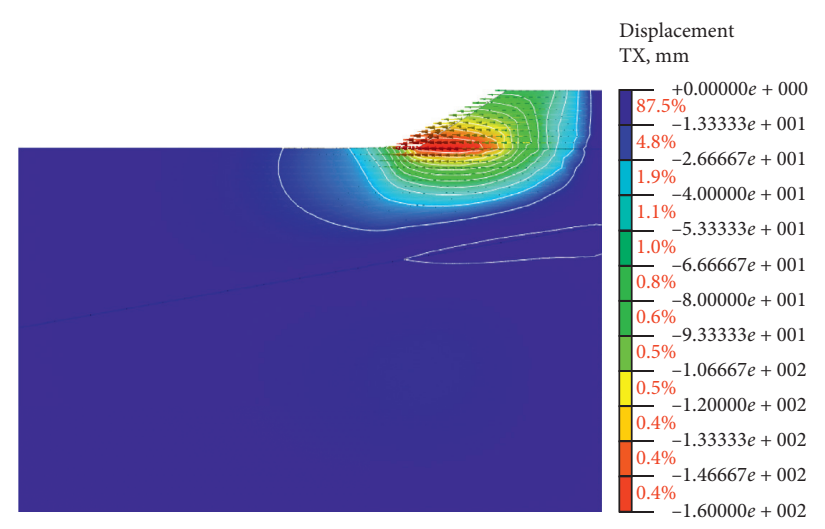

(a)

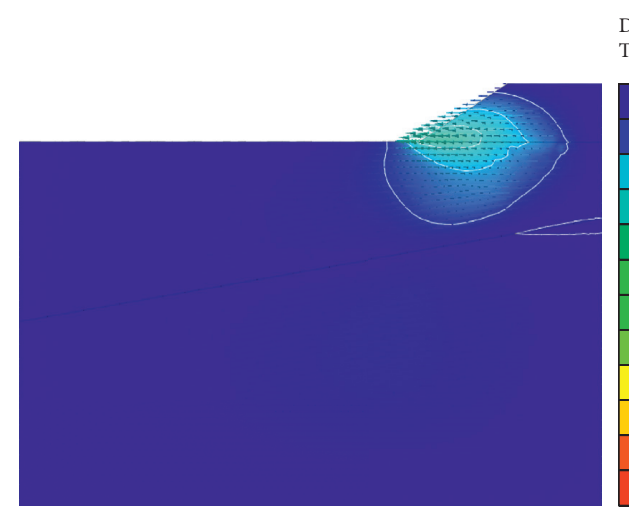

(c)

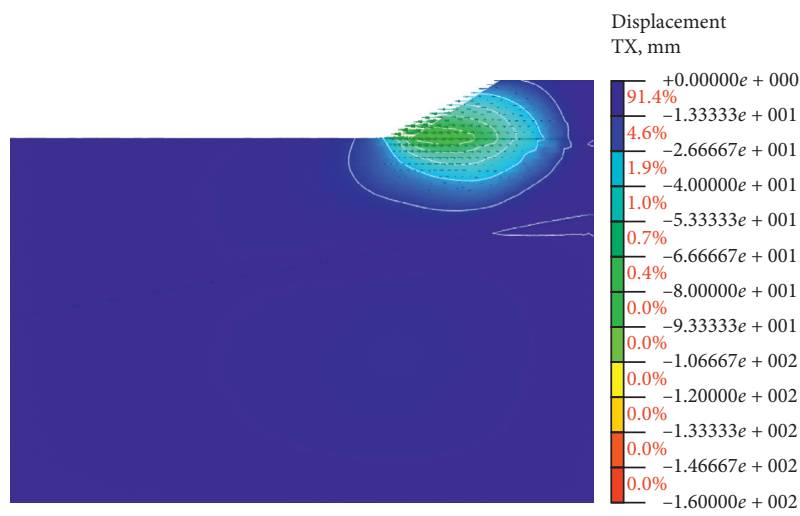

(b)

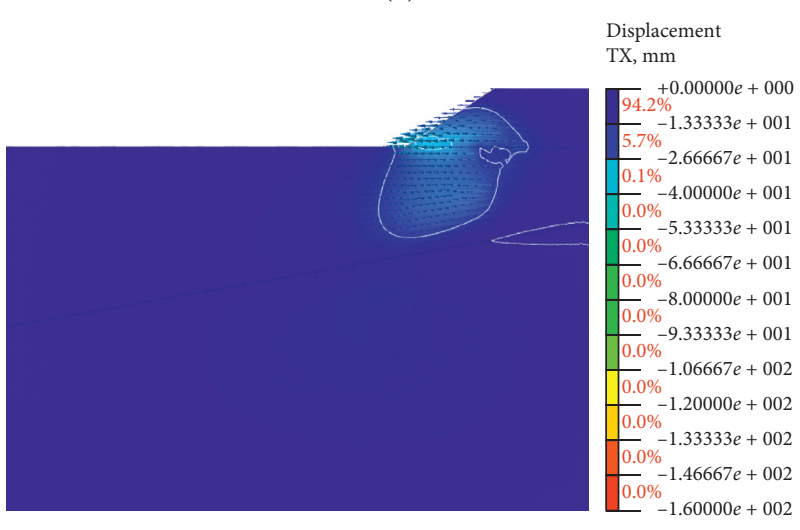

(d)

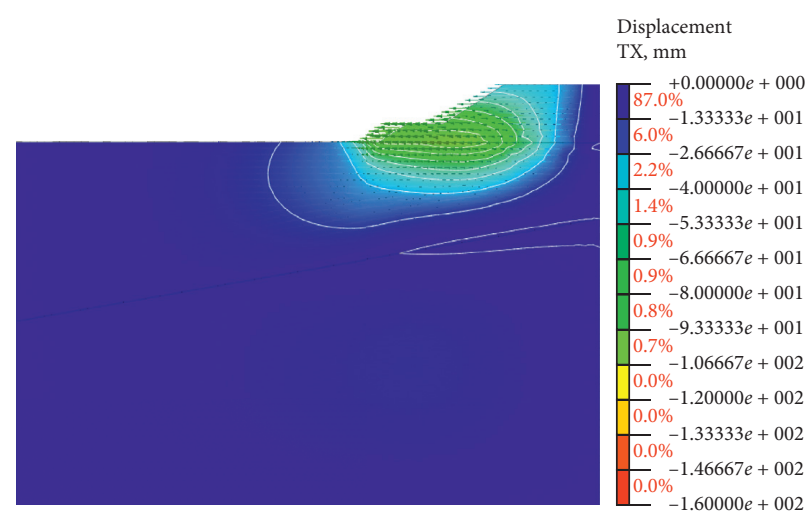

(e)

Figure 9: Horizontal deformation of the foundation. (a) Program A, (b) Program B, (c) Program C, (d) Program D, and (e) Program E.

the relatively small vertical load of the embankment slope. Moreover, inclined PCP piles are favored by their strong lateral reinforcement effects that can effectively prevent the lateral soil movement under the embankment. Therefore, they are important contributors to reinforcement of the middle part of the embankment. 


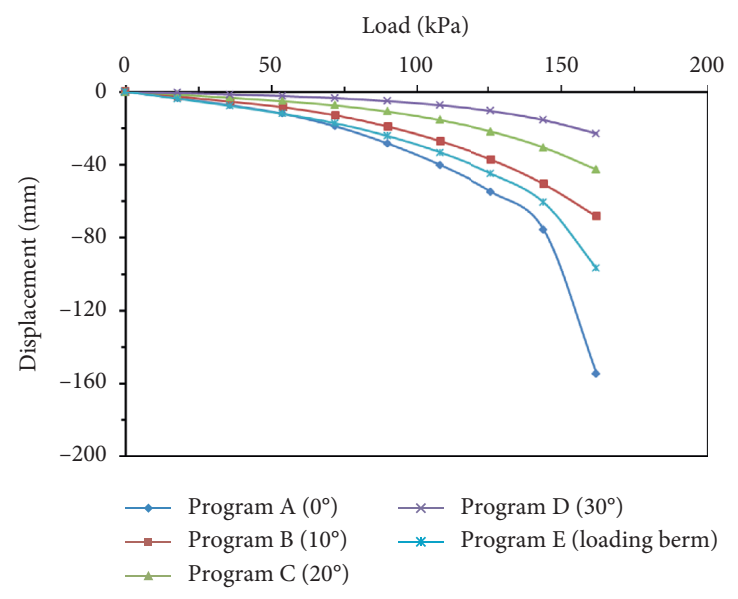

(a)

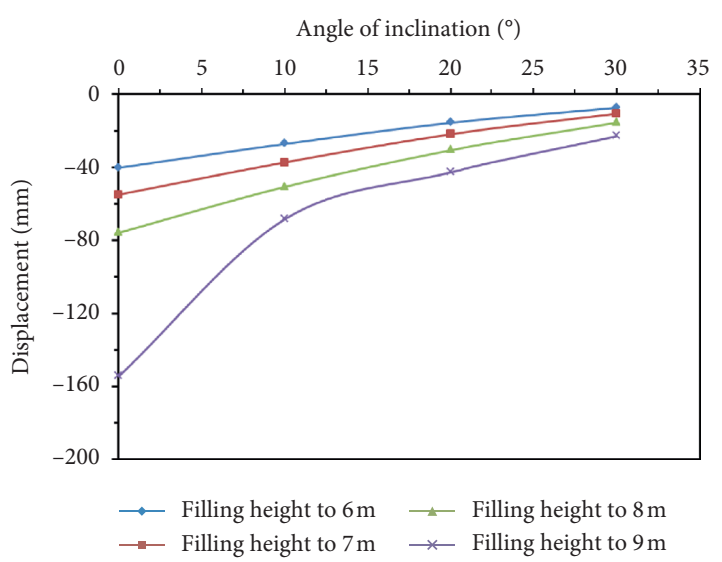

(b)

FIgure 10: Variations of maximum displacement. (a) Change with loads and (b) change with inclination angles.

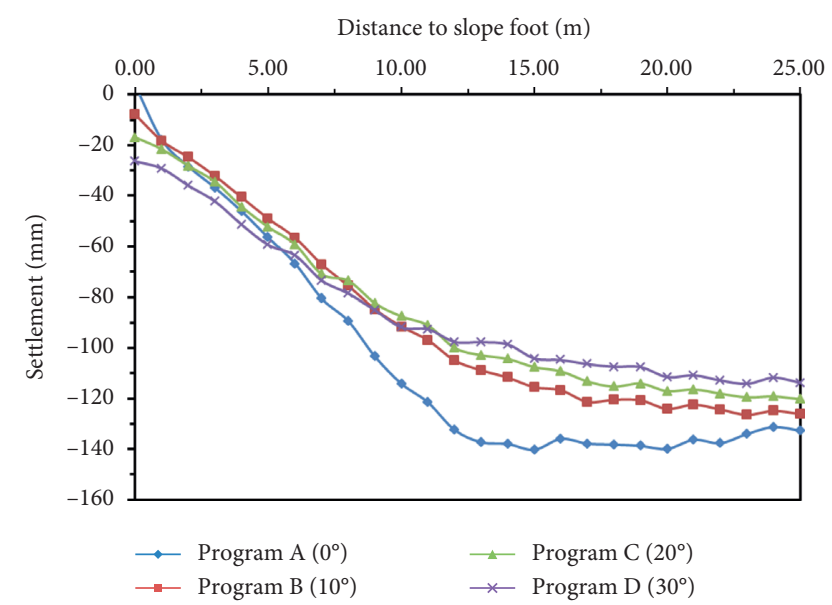

FIGURE 11: Settlement distribution curves of the embankment bottom surface.

4.3. Pile Bending Moment. According to Zheng et al. [7, 8], fracturing and overturning of rigid piles are highly responsible for the embankment collapse. Therefore, it is crucial to analyze the stress state of the PCP piles and judge whether they are damaged, so as to evaluate the overall stability of the foundation.

Figure 12 shows the bending moment distribution of PCP piles in different reinforcement programs. The following conclusions can be drawn:

(1) Programs A and E are featured by the dominant occurrence of the bending moment on the upper part of the piles, and the bending moment first increases and, then, decreases along the pile length from the top to bottom. PCP piles under the middle part of the embankment are subjected to relatively small bending moment, while those under the embankment slope are subjected to relatively large bending moment. The maximum bending moment value appears in the PCP pile under the embankment slope foot (pile A), which is prone to bending failure in the process of embankment filling.

(2) Program B shares similarity with Program A in the bending moment distribution of PCP piles. The piles under the middle embankment also suffer relatively small bending moment, while those under the embankment slope are subjected to relatively large bending moment. The maximum bending moment also appears in the upper part of pile A. However, Programs $\mathrm{C}$ and $\mathrm{D}$ present different features from the abovementioned two, with large bending moment also appearing in the lower part of the pile body under the middle part of the embankment (pile B).

According to the abovementioned analysis, PCP piles in all reinforcement programs have large bending moments under the load of the embankment. When the bending moment exceeds a certain threshold, PCP piles are broken, and then, the reinforcement fails, resulting in slip and collapse of the embankment. In all the reinforcement programs, the maximum bending moments mainly appear on piles $\mathrm{A}$ and $\mathrm{B}$. Therefore, by comparing and analyzing distributions of bending moments of the two rows of piles, it is possible to obtain the bending failure loads of the PCP piles in different reinforcement programs. Furthermore, the influence of the pile inclination angle on the foundation bearing capacity is elaborated. Figures $13(\mathrm{a})$ and 13(b) show bending moment distribution curves of piles $\mathrm{A}$ and $\mathrm{B}$ in different reinforcement programs when the embankment filling reaches $9 \mathrm{~m}(166 \mathrm{kPa})$. The following conclusions can be drawn:

(1) Pile A mainly suffers the bending moment in the upper part of the pile body. The bending moment first increases and, then, decreases along the pile length from the top to bottom, and the maximum value appears at the position of $2-5 \mathrm{~m}$ from the pile top. In terms of the maximum bending moment, Program A has the largest value, which is $0 \%$, 


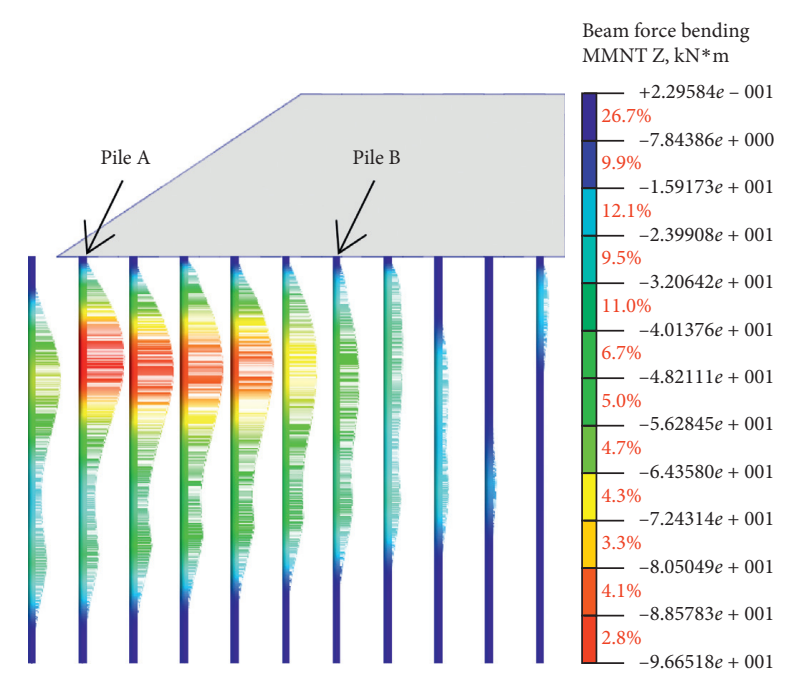

(a)

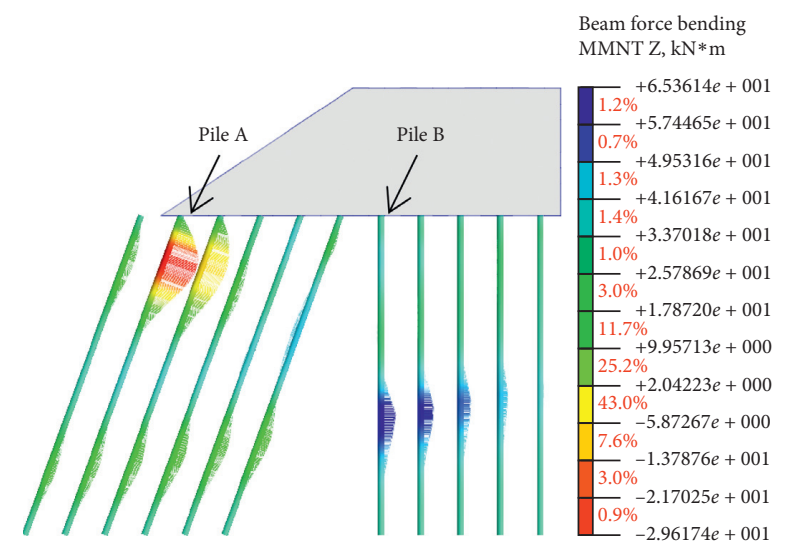

(c)

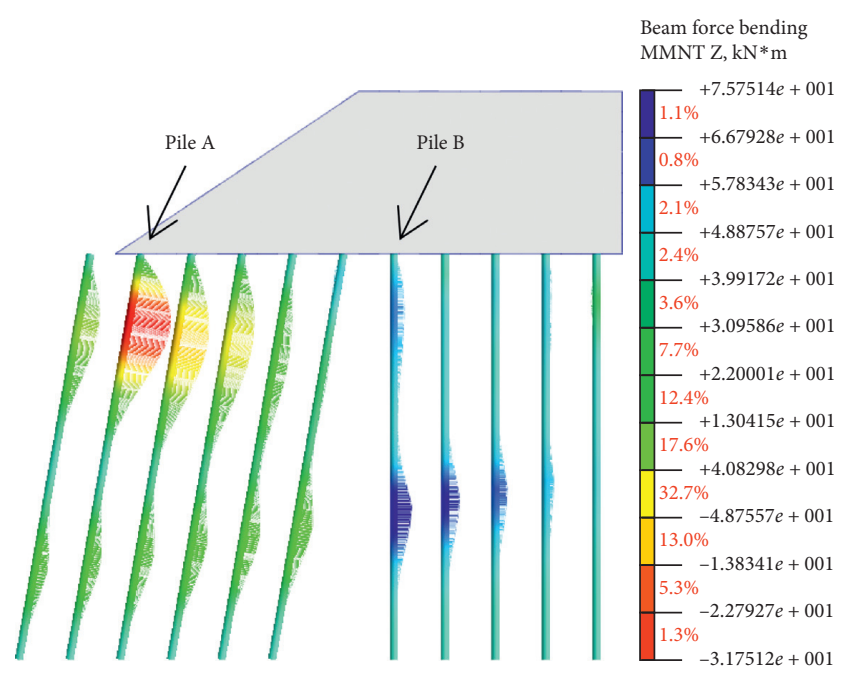

(b)

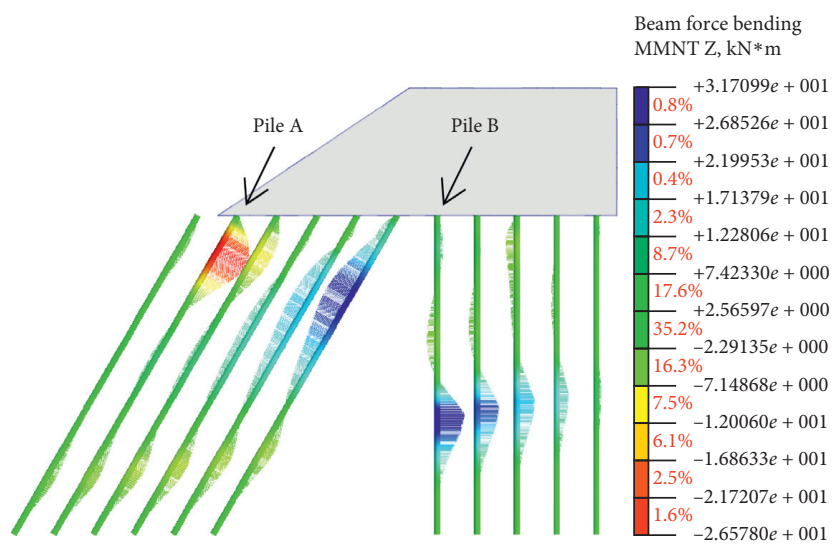

(d)

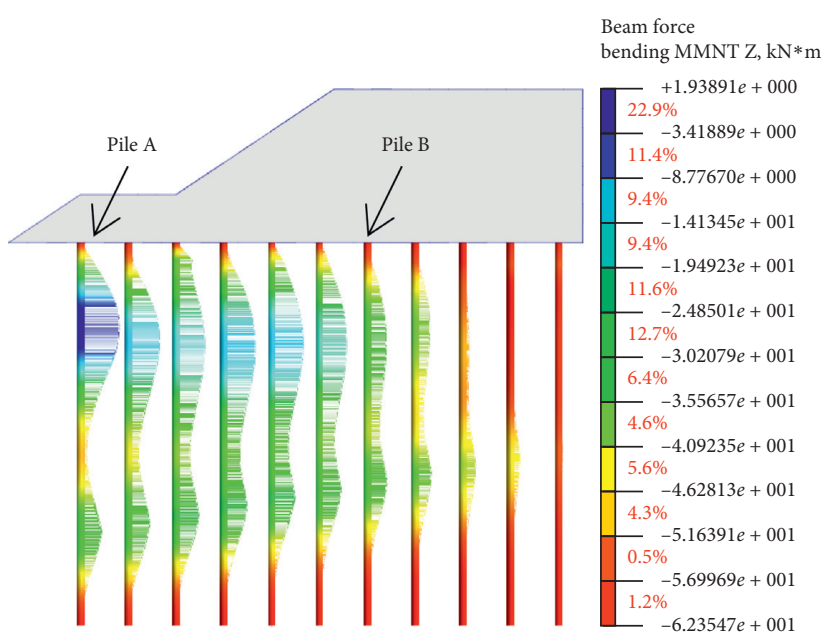

(e)

Figure 12: Bending moment distribution of PCP piles. (a) Program A, (b) Program B, (c) Program C, (d) Program D, and (e) Program E.

followed by Programs B (10\%), C (20\%), E (loading berm), and $\mathrm{D}(30 \%)$. The maximum bending moment value is found to decrease as the pile inclination angle increases, accompanied by the decreasing probability of pile bending failure. The maximum bending moment of Program E (loading berm) is smaller than that of Program A $(0 \%)$ but larger than that of Program D (30\%), which indicates the advantage of the loading berm in more effectively reducing the bending moment of the pile body, as well 


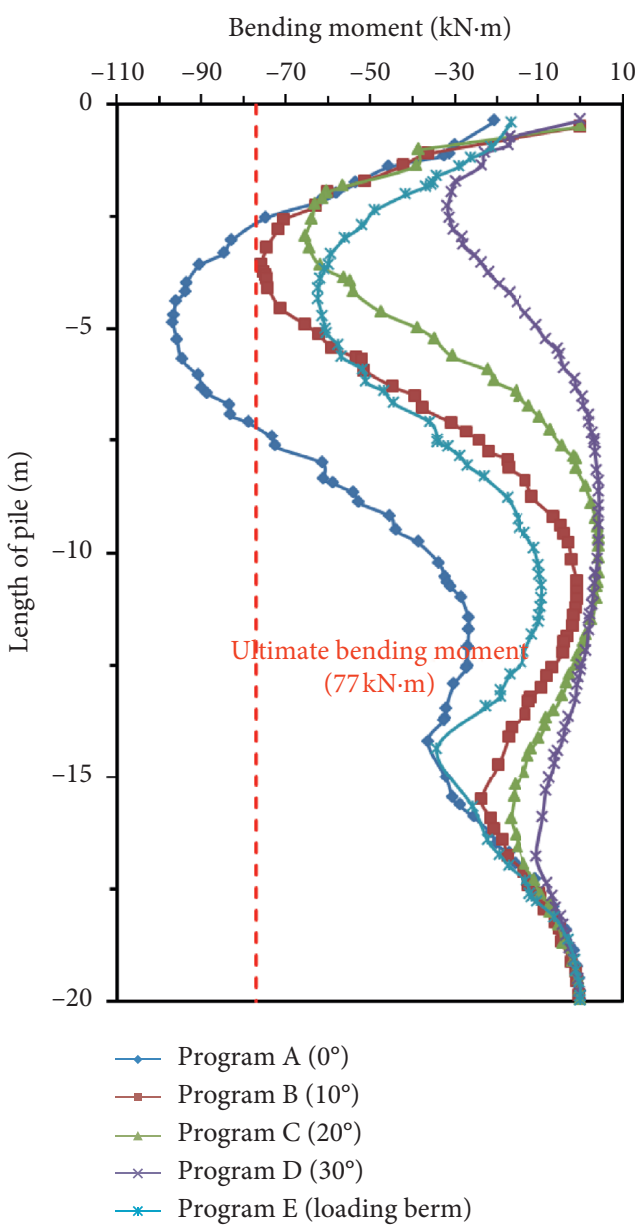

(a)

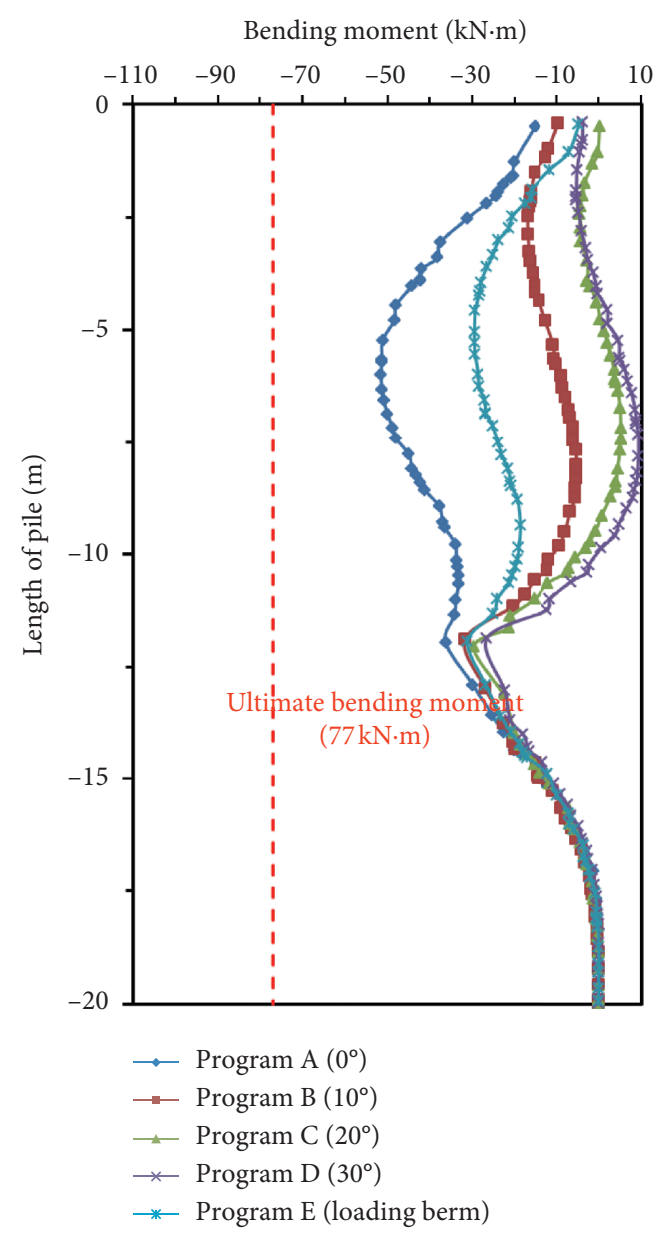

(b)

Figure 13: Bending Moments of PCP piles. (a) Pile A and (b) pile B.

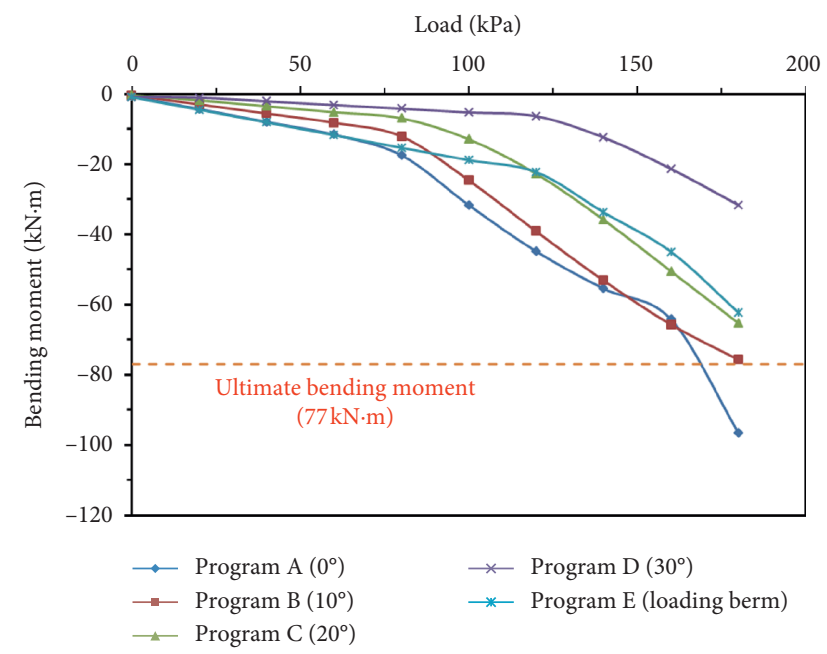

(a)

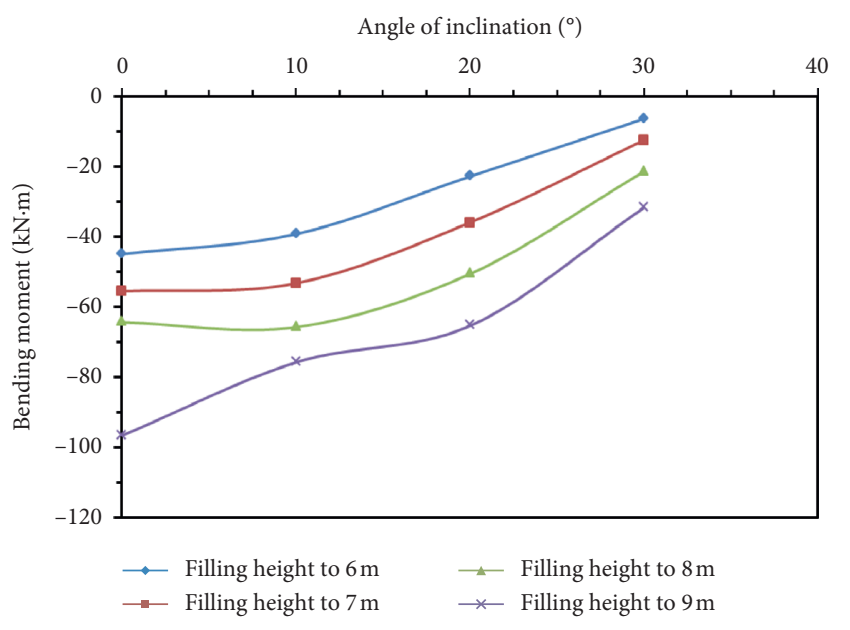

(b)

FIgURE 14: Variations of the maximum bending moments. (a) Change with loads and (b) change with inclination angles. 
as its poorer reinforcement effect than the inclined pile.

(2) As for pile B, large bending moments occur in both upper and lower parts of the pile body. There are two maximum values in the pile body, which are located at $2-5 \mathrm{~m}$ and $12 \mathrm{~m}$ from the pile top, respectively. Different reinforcement programs share basically the same maximum bending moment for the lower part of the pile body, but they have obviously different maximum bending moments for the upper part of the pile body. Specifically, Program A has the largest maximum bending moment, which is $0 \%$, followed by Program E (Loading berm), Programs B (10\%), C $(20 \%)$, and D (30\%). Meanwhile, the maximum bending moment of pile $\mathrm{B}$ also decreases as the inclination angle increases.

(3) The PCP piles used in the actual project are $400 \times 70 \mathrm{~mm}$ in dimensions, with ultimate pile body bending moments of $77 \mathrm{kN} \mathrm{m}$. As shown in Program A, when the embankment filling height reaches $9 \mathrm{~m}$ $(162 \mathrm{kPa})$, the pile body bending moment exceeds the ultimate bending moment, resulting in pile body damage and consequent invalid foundation reinforcement. Therefore, it is not feasible to use vertical PCP piles for soft foundation reinforcement.

Figure 14(a) shows variations of the maximum bending moments of pile A with loads in the process of embankment filling, while Figure 14(b) shows variations of the maximum bending moments of pile A with the pile inclination angle under different embankment filling heights. The following conclusions can be drawn:

(1) For Program A, the maximum bending moment value does not change much with the increase of load, when the upper load is less than $60 \mathrm{kPa}$ (filling height $3.3 \mathrm{~m}$ ). In comparison, as the vertical load is larger than $60 \mathrm{kPa}$ and continues to increase, the maximum bending moment increases rapidly, reaching the ultimate bending moment at a load of $150 \mathrm{kPa}$ (filling height $8.3 \mathrm{~m}$ ). At that moment, pile A is already subjected to bending failure, and further increasing the filling height is bound to cause bending failures of nearby PCP piles, which will lead to reinforcement failure and overturning of the embankment slope.

(2) Program B shares similarity with Program A in terms of the maximum bending moment, which is also relatively stable with small loading $\left(P<60^{\circ} \mathrm{kPa}\right)$ and increases rapidly when the load is larger than $60 \mathrm{kPa}$ and further grows. However, compared with bending failure in Program A, that in Program B occurs much later at a load of $162 \mathrm{kPa}$ (filling height $9 \mathrm{~m}$ ). As for Programs $\mathrm{C}$ and $\mathrm{D}$, no bending failures are observed until the embankment filling height reaches the design value of $9 \mathrm{~m}(162 \mathrm{kPa})$, as their maximum bending moments are much smaller than the ultimate bending moment $(77 \mathrm{kN} \cdot \mathrm{m})$.
According to the abovementioned analysis, when using PCP piles to reinforce the soft soil foundation to withstand the upper embankment load, it is effective to increase the PCP pile inclination angle at the lower part of the slope so as to well reduce the maximum bending moment and prevent the pile body from bending failure, which is beneficial to the overall reinforcement effect of the foundation. When the pile inclination angle is larger than $20^{\circ}$, the maximum bending moment is obviously smaller than that of Program E using a loading berm for reinforcement.

\section{Conclusions}

Based on the analysis of an actual engineering accident with embankment slope collapse, this study proposes to use inclined PCP piles with different inclination angles to reinforce the embankment foundation and establishes a finite element analysis model for evaluation of their performances, including their effects on horizontal displacement, vertical settlement, and pile bending moment. The main conclusions are as follows:

(1) The maximum horizontal displacement of the foundation is located at the foot of the embankment slope. Specifically, reinforcement using inclined PCP piles and loading berms contributes to smaller maximum horizontal displacement of the foundation than that using vertical PCP piles. Moreover, in terms of the lateral reinforcement effect, inclined PCP piles present better performances than loading berms. Also, as the inclination angle increases, the maximum horizontal displacement decreases rapidly, associated with greatly enhanced lateral stability.

(2) The vertical settlement of the embankment slope increases as the inclination angle increases, though the increasing magnitude is small. In comparison, the vertical settlement of the middle part of the embankment decreases as the inclination angle increases. Compared with vertical PCP pile-reinforced foundations, inclined PCP pile-strengthened ones present smaller vertical settlement in the middle part of the embankment, which means good vertical reinforcement effects.

(3) PCP piles in the lower part of the embankment are subjected to bending moment, with their maximum value appearing in the upper part of the PCP pile at the embankment slope foot. In the process of embankment filling, the maximum pile bending moment may reach the ultimate bending load, followed by occurrence of bending failure. In this context, it is effective to reduce the maximum bending moment and prevent the pile body from bending failure through increasing the inclination angle of PCP piles in the lower part of the slope, which is beneficial to the overall reinforcement effect of the foundation.

To conclude, inclined PCP piles significantly contribute to improvement of lateral stability, vertical bearing capacity, 
and pile body stress characteristics, and an inclination angle of $30^{\circ}$ is suggested to be the optimum value for strengthening the embankment slope in the practical engineering. The abovementioned conclusions are applicable to other projects with comparable geological conditions, while more efforts should be paid to evaluate engineering characteristics and reinforcement effects of inclined PCP piles if there are great differences in engineering geological conditions.

\section{Data Availability}

The data used to support the findings of this study are available from the corresponding author upon request.

\section{Conflicts of Interest}

The authors declare that they have no conflicts of interest.

\section{Acknowledgments}

This work was financially supported by the National Natural Science Foundation of China (No. 51378083), Scientific Research Fund of Hunan Provincial Education Department (19A), the Open Research Fund of Science and Technology Innovation Platform of Bridge Engineering of Changsha University of Science and Technology (No. 18KA02), the Hunan Provincial Innovation Foundation for Postgraduate (CX2018B538), the Hunan Provincial Natural Science Foundation, China (2020JJ4619), and the Natural Science Foundation of Hunan Provincial Department of Education (19A034), which are all greatly appreciated.

\section{References}

[1] M. Terashi, H. Tanaka, and M. Kitazume, "Extrusion failure of the ground improved by the deep mixing method," in Proceedings of the 7th Asian Regional Conference on Soil Mechanics and Foundation Engineering, pp. 313-318, Haifa, Israel, November 1983.

[2] M. Miyake, H. Akamoto, and M. Wada, Deformation Characteristics of Ground Improved by a Group of Treated Soil, Balkema, Rotterdam, Netherlands, 1991.

[3] H. Hashizume, Y. Okochi, J. Dong et al., "Study on the behavior of soft ground improved using deep mixing method," in Proceedings of the International Conference on Centrifuge, pp. 851-856, Tokyo, Japan, September 1998.

[4] M. Kitazume, K. Orano, and S. Miyajima, "Centrifuge model tests on failure envelope of column type deep mixing method improved ground," Soils and Foundations, vol. 40, no. 4, pp. 43-55, 2000.

[5] M. Kitazume and K. Maruyama, "External stability of group column type deep mixing improved ground under embankment loading," Soils and Foundations, vol. 46, no. 3, pp. 323-340, 2006.

[6] M. Kitazume and K. Maruyama, "Internal stability of group column type deep mixing improved ground under embankment loading," Soils and Foundations, vol. 47, no. 3, pp. $437-455,2006$.

[7] G. Zheng, L. Liu, and J. Han, "Stability of embankment on soft subgrade reinforced by rigid piles (I)-Background and single pile analysis," Chinese Journal of Geotechnical Engineering, vol. 32, no. 11, pp. 1648-1657, 2010.
[8] G. Zheng, L. Liu, and J. Han, "Stability of embankment on soft subgrade reinforced by rigid inclusions (II)-group piles analysis," Chinese Journal of Geotechnical Engineering, vol. 32, no. 12, pp. 1811-1820, 2010.

[9] G. Zheng, S. Li, and Y. Diao, "Centrifugal model tests on failure mechanisms of embankments on soft ground reinforced by rigid piles," Chinese Journal of Geotechnical Engineering, vol. 34, no. 11, pp. 1977-1989, 2012.

[10] F. Liu and J. Zhang, "Centrifuge test on deformation characteristics of pile-geogrid composite foundation in soft soil under slope," Chinese Journal of Rock Mechanics and Engineering, vol. 37, no. 1, pp. 209-219, 2018.

[11] J. Bi, G. Gao, and J. Zhang, "Model test study on the failure mechanisms of the geogrid-reinforced and pile-supported foundation on soft soil with overlying sloping base," Journal of Harbin Institute of Technology, vol. 52, no. 2, pp. 1-11, 2018.

[12] X. Gu, X. Tan, W. Huang et al., "Failure mechanisms of embankment on inclined soft foundation reinforced by CFG Piles," Chinese Journal of Geotechnical Engineering, vol. 39, no. S1, pp. 111-115, 2017.

[13] Y. Xie, S.-H. Zhang, and D.-Q. Zhou, "Experimental study of mechanical behavior of passive loaded piles adjacent to piled foundation," KSCE Journal of Civil Engineering, vol. 22, no. 10, pp. 3818-3826, 2018.

[14] S. S. Rajashree and T. G. Sitharam, "Nonlinear finite-element modeling of batter piles under lateral load," Journal of Geotechnical and Geoenvironmental Engineering, vol. 127, no. 7, pp. 604-612, 2001.

[15] G. Zheng, X. N. Gong, Y. Xie et al., "State-of-the-art techniques for ground improvement in China," China Civil Engineering Journal, vol. 45, no. 2, pp. 127-146, 2012.

[16] M. Modano, F. Fabbrocino, A. Gesualdo et al., "On the forced vibration test by vibrodyne," in Proceedings of 5th ECCOMAS Thematic Conference on Computational Methods in Structural Dynamics and Earthquake Engineering, pp. 209-217, Rethymno, Greece, December 2015.

[17] X. N. Gong, "Generalized composite foundation theory and engineering application," Chinese Journal of Geotechnical Engineering, vol. 29, no. 1, pp. 1-13, 2007.

[18] H. L. Liu and M. H. Zhao, "Review of ground improvement technical and its application in China," China Civil Engineering Journal, vol. 49, no. 1, pp. 96-115, 2016.

[19] F. Fabbrocino, I. Farina, and M. Modano, "Loading noise effects on the system identification of composite structures by dynamic tests with vibrodyne," Composites Part B: Engineering, vol. 115, pp. 376-383, 2017.

[20] L. Wang and G. Zheng, "Research on vertical bearing capacity of partially inclined pile with finite element method," Rock and Soil Mechanics, vol. 30, no. 11, pp. 3533-3538, 2009.

[21] W. Cao, Q. Lu, W. Fan et al., "Experimental study of load transfer behavior of batter piles under vertical loads," Rock and Soil Mechanics, vol. 37, no. 11, pp. 3048-3056, 2016.

[22] J. Xu, W. Gong, Q. Zhang et al., "Numerical simulation and field test study on vertical bearing behavior of large diameter steel of inclined piles," Rock and Soil Mechanics, vol. 38, no. 8, pp. 2434-2447, 2017.

[23] D.-Q. Zhou and C.-X. Feng, "Engineering characteristics and reinforcement program of inclined pre-stressed concrete pipe piles," KSCE Journal of Civil Engineering, vol. 23, no. 9, pp. 3907-3923, 2019. 